\title{
El nuevo clientelismo político en el siglo XXI: Colombia y Venezuela 1998-2010
}

Josué Alexandro BARÓN*

Artículo recibido: 29 de septiembre de 2014

Artículo aprobado: 13 de abril de 2015

Doi: dx.doi.org/10.12804/desafios27.2.2015.08

Para citar este artículo: Barón, J. A. (2015). El nuevo clientelismo político en el siglo xxi: Colombia y Venezuela: 1998-2010. Desafios, 27(II), 253-289. Doi: dx.doi.org/10.12804/ desafios27.2.2015.08

\section{Resumen}

Existe un debate alrededor del problema de 'la nueva etapa' de clientelismo politico en relación con la que se estableció en el pasado por los partidos políticos. Este trabajo se centra en explicar las dinámicas que esta etapa del clientelismo tiene, en donde el Estado, sus instituciones, el gobierno y las politicas sociales juegan un papel central. Para esto, hago un análisis comparado entre los gobiernos de Hugo Chávez (Ven.) y Álvaro Uribe (Col.), teniendo como referente las políticas sociales, el papel del presidente y las redes que se arman alrededor de este proceso. Como resultado, muestro evidencia de la existencia de una nueva etapa del clientelismo político, la cual se sustenta en prácticas como la utilización de las políticas públicas $y$ de las instituciones estatales para organizar una red clientelista. ¿Con qué fin? El de conseguir apoyo electoral para el gobernante de turno. Asi mismo, demuestro que dichas prácticas están más estructuradas en Venezuela, toda vez que existe una mayor centralización del poder, mientras que, en Colombia, las prácticas son

\footnotetext{
* Magíster en Análisis de Problemas Políticos, Económicos e Internacionales Contemporáneos de la Academia Diplomática en cooperación con la Universidad Externado de Colombia. Asesor político e investigador independiente. Correo electrónico: alitos2012@ hotmail.com
} 
menos estructuradas, pero igualmente encaminadas a sumar votos. Finalmente, este proceso termina generando: una nueva relación entre el Estado y los ciudadanos, una recentralización del poder y una dependencia del ciudadano frente al Estado. Palabras clave: Estado, gobierno, partidos políticos, clientelismo y políticas sociales.

\title{
The New Political Clientelism in the XXI Century: Colombia and Venezuela: 1998-2010
}

\begin{abstract}
The literature on the 'new age' of political clientelism discusses how political parties established their clientilist networks. This article explains the inner dynamics of clientelism, specifically the role played by the state, its institutions, the government, and social policies. I compare the social policies, presidential roles, and constructed networks of the governments of Hugo Chávez in Venezuela and Alvaro Uribe in Colombia. In addition, the article provides evidence of the "new age" of political clientelism, which is based on the utilization of public policies or state institutions to form a clientelistic network in order to elect its favored candidate. The article demonstrates that such practices are bighly structured in Venezuela due to the strong centralization of power in the government. By contrast, in Colombia, clientelism is less structured. However, political clientelism still focuses on obtaining the highest possible number of votes. Finally, I examine how these processes shed light on new state-citizen interactions, a re-centralization of power, and the dependency of the citizens on the state.
\end{abstract}

Keywords: State, government, political parties, clientelism, social policies.

\section{As novas dinâmicas do clientelismo político: a Colômbia e a Venezuela 1998-2010. Uma aproximação ao problema desde uma perspectiva comparada}

\begin{abstract}
Resumo
Existe um debate ao redor do problema da "nova etapa" de clientelismo politico em relação com a que se estabeleceu no passado pelos partidos políticos. Este trabalho centra-se em explicar as dinâmicas que esta etapa do clientelismo tem, onde o Esta-
\end{abstract}


do, suas instituiçöes, o governo e as politicas sociais desempenham um papel central. Para isto, faço uma análise comparada entre os governos de Hugo Chávez. (Ven.) e Alvaro Uribe (Col.), tendo como referente as politicas sociais, o papel do presidente $e$ as redes que se conformam ao redor deste processo. Como resultado, mostro evidência da existência de uma nova etapa do clientelismo político, a qual sustenta-se em práticas como a utilização das políticas públicas e das instituições estatais para organizar uma rede clientelista. Com que fim? Conseguir apoio eleitoral para o governante de turno. Igualmente, demostro que ditas práticas estão mais estruturadas na Venezuela, toda vez que existe uma maior centralização do poder, enquanto que, na Colômbia, as práticas são menos estruturadas, mas igualmente encaminhadas a adicionar votos. Finalmente, este processo termina gerando: uma nova relação entre o Estado e os cidadãos, uma recentralização do poder, e uma dependência do cidadão frente ao Estado.

Palavras-chave: Estado, governo, partidos politicos, clientelismo e politicas sociais.

\section{Las dinámicas del clientelismo, una reflexión teórica a manera de introducción}

Sin lugar a dudas, el clientelismo político como práctica política y electoral se ha venido trasformando, esto no quiere decir que su implementación por parte de los partidos políticos haya desaparecido. Desde hace casi dos décadas, asistimos a la configuración de una nueva etapa del clientelismo, la cual se ha identificado como 'clientelismo de Estado'. Aquí confluyen nuevas dinámicas, nuevos actores que reordenan las redes clientelistas desde el nivel nacional hasta el local. Por lo tanto, el artículo analiza las dinámicas de esta nueva etapa del clientelismo político.

En este orden de ideas, este texto muestra que efectivamente en Colombia y Venezuela hoy asistimos a una nueva etapa del clientelismo político. Que existen unas nuevas dinámicas, nuevos actores, que se centran en la utilización de los recursos estatales mediante el establecimiento de políticas públicas, que, en principio, buscan aliviar algunas problemáticas sociales, pero que muchas veces terminan generando apoyo electoral a los gobiernos de turno. Este proceso establece una nueva relación entre el Estado y los ciudadanos, en la medida que 
se hace uso de las instituciones del Estado y de los recursos para organizar unas redes, que se convierten en transmisoras de las prácticas clientelistas establecidas por el presidente. Lo que finalmente termina en una recentralización del poder, reducción de la participación y genera más bien una dependencia del ciudadano frente al Estado. El artículo se divide en dos partes, en la primera se hace una reflexión teórica y un apunte histórico reciente; en la segunda, se explica la configuración y operación de esta nueva etapa del clientelismo, para finalmente concluir.

\subsection{Apuntes sobre el clientelismo político}

Es preciso apuntar que el Estado moderno se caracteriza por una serie de propiedades que lo identifican: la soberanía, la libertad, su relación con la nación, el uso de la fuerza legítima y la construcción de la democracia, entre otros. En palabras de Weber: "El Estado es aquella comunidad humana que en el interior de un determinado territorio (...) reclama para sí (con éxito) el monopolio de la coacción física legítima. Porque lo específico de la realidad es que a las demás asociaciones o personas individuales sólo se les concede el derecho de la acción física en la medida en que el Estado lo permite" (Weber, 2002, p. 1056). En este sentido, el Estado moderno ha tejido unas relaciones con la sociedad, a partir de la coerción y mediante la representación. En tal orden de ideas, como sostiene O’Donnell, "el Estado es también, y no menos primariamente, un conjunto de relaciones sociales que establece cierto orden en un territorio determinado..." (O’Donnell en Santana, 1995). En tanto, el Estado está llamado a promover los escenarios adecuados para que se establezcan unas buenas relaciones con los ciudadanos, en donde concurran los disensos y se busquen los consensos, basados en procesos de representación y participación, esto al menos en el ideal liberal.

La mayoría de los Estados modernos construyen la democracia como una forma de gobierno, en tanto les permite establecer, al menos, una limitada relación con la sociedad. La aparición de los partidos políticos en cierta medida contribuye a sostener esta relación y mantener la representación de la sociedad en el Estado. Esta articulación que 
lograron los partidos políticos entre la sociedad civil y el Estado, en un primer momento, se establece medianamente, en Colombia y Venezuela, gracias a cierto grado de ideología. Diversas circunstancias, como la violencia en Colombia, la centralización del poder en Venezuela, la debilidad del mismo Estado como lugar de resolución de conflictos, la fragmentación de los partidos políticos en ambos casos, habrían llevado a "pasar dicho sistema y sus partidos de una legitimación ideológica hacia una legitimación puramente utilitaria” (Njaim, 1996, p. 141). Esto nos permite observar cómo se van transformando los elementos que han articulado el sistema político, en la medida que de ellos depende la legitimación del Estado frente a la sociedad.

En tal sentido, una de las maneras mediante las cuales el Estado y sus autoridades se legitiman son los procesos electorales, los cuales, junto a la ley, le permiten a la sociedad civil, limitadamente, ser representada en el Estado. Tales elecciones en un primer momento estaban motivadas por la ideología, esto con respecto a los partidos políticos, pero ahora se habría cambiado por la mercantilización, lo que lleva a que la acción mediante la cual se realiza el ritual de representación se torne limitadamente libre. Se anteponen, entonces, las lealtades, las cooptaciones, la exclusión y, en ocasiones, las amenazas a los electores. Esto no quiere decir que, cuando opera la ideología, las cosas sean diferentes, lo que pasa es que tales prácticas son menos evidentes.

De este modo, prácticas tradicionales como la de lealtad y cooptación (que casi siempre es negociación de favores entre elector y elegido) se fortalecen y se transforman, muchas veces por los agentes del Estado para la legitimación y funcionamiento de este frente a la sociedad. Este tipo de acciones se han enmarcado en lo que se conoce como prácticas clientelistas. El clientelismo en el contexto político se desarrolla con más fuerza desde lo estatal, apoyándose en la utilización de recursos públicos, puestos de trabajo, entre otros. En este sentido, entendemos el clientelismo como una práctica que se sustenta en utilizar los recursos públicos "para implementar las relaciones políticas de clientela, que constituyen el aspecto central de la mediación 
estatal y, por tanto, del carácter moderno -nuevo- del fenómeno" (Leal \& Dávila, 1990, p. 44). Tales relaciones de clientela tienen de por medio el poder, poder que es ejercido por el patrón sobre el cliente, en términos políticos y electorales, relación que se da entre el jefe político y el elector, a nivel local regional y nacional, en donde cada uno busca obtener sus propios dividendos.

Según se establece el clientelismo como práctica política, asume dos valores centrales. Szwarcberg afirma que, por un lado, se encuentra su valor "instrumental y se concentran tan sólo en la pura distribución de bienes, es decir, en su costado más visible y escandaloso (favores por votos). El segundo valor está relacionado con un fuerte componente simbólico cuya centralidad y relevancia no puede, ni debe, ser obviada en los análisis que buscan comprender en forma adecuada el fenómeno” (Szwarcberg, 2001, p. 5).

En este orden de ideas, el clientelismo político "en su nuevo papel de articulador del sistema, la mediación se limitó a las demandas sociales que fueran susceptibles de transformarse directamente en votos" (Leal \& Dávila, 1990, p. 91) y apoyos políticos significativos. La forma en que se expresa este clientelismo es diversa, pero tiene como centro el intercambio de favores entre el representante del Estado y el ciudadano. Identificamos los favores más comunes: subsidios, dinero, privilegios, prestación de servicios, empleos y recomendaciones para los clientes dentro del Estado.

Teniendo en cuenta lo anterior, el clientelismo se ha desarrollado, al menos, en tres niveles o etapas: el clientelismo desinstitucionalizado (tradicional), el clientelismo de partidos políticos (clientelismo moderno) y, por último, el clientelismo promovido desde las mismas instituciones públicas por agentes del Estado (clientelismo desde el Estado).

Clientelismo desinstitucionalizado: se conoce como la práctica más antigua de clientela y tiene mayor fortaleza en el ámbito local. En este proceso, se crean los círculos de potestad para controlar el poder local, en donde el jefe político era el gamonal o cacique y su contraparte el cliente o seguidor. Se buscaba lealtad a cambio de protección 
entre los dos actores. Luego, esto se traslada al campo político en donde "el compadrazgo y el favor personal constituían mecanismos de supervivencia comunitaria, confundiéndose a la vez con las relaciones de poder" (Leal, 1989, p. 174). Tales relaciones de poder, en buena medida, son informales, o por lo menos no mediadas por los partidos políticos, o por los agentes del Estado o sus instituciones. En este sentido, Caciagli define estas relaciones como "relaciones informales de poder" (1996, p. 17).

Clientelismo desde los partidos políticos: los partidos políticos habían logrado establecer más o menos la ideología como la manera de relacionarse o articular las demandas sociales de los ciudadanos frente al Estado, esto sucedió en varios países de América Latina; Colombia y Venezuela no fueron la excepción. En estos dos países, los partidos políticos, en cierta medida, lograron en un principio articular las demandas sociales mediante ideologías. Sin embargo, este proceso no perduró en el tiempo, y pronto se optó por otros medios para lograr respaldo político y electoral de la sociedad. Como sostiene Leal, para el caso de Colombia, "a medida que, en distintos grados, se fue perdiendo la mística familiar de pertenencia a uno u otro de los partidos tradicionales como efecto del Frente Nacional (1958-1974), las gratificaciones emocionales partidistas fueron truncándose por la búsqueda de algún favor burocrático o económico como condición de fidelidad partidista" (Leal, 1989, p. 174). Esto va influyendo en el cambio del apoyo de los ciudadanos a los partidos; disminuye la afiliación ideológica; se incrementan y refuerzan las afiliaciones de carácter más económico y de tipo personal.

En su relación con el Estado, los partidos políticos empiezan a perder su capacidad de representación de las demandas sociales, en tanto buscan los medios de recuperar parte del terreno perdido y el manejo de recursos oficiales les permite construir relaciones clientelistas con sus seguidores. Con respecto a esto, Leal sostiene que "el rápido aumento de los recursos del Estado sirvió para alimentar las relaciones clientelistas, pues a la desvalorización de la ideología de pertenencia a los partidos se le opuso la necesidad de afiliación a ellos como condición para aspirar a los beneficios que brindaba 
la cobertura amplia del Estado" (1989, p. 175). Sumado a ello, los favores inmediatos, como trámites de documentos, servicios y hasta materiales para construcción, fueron las trampas de los partidos para capturar respaldo político y electoral.

En este sentido, cuando los partidos no responden de manera eficiente a la problemática social y su relación con la sociedad es casi meramente clientelista, aparece un nuevo actor: los políticos extrapartidos, quienes se muestran como candidatos que buscan reducir o poner fin a las prácticas amañadas de los partidos políticos y sus representantes en el gobierno. Los casos de Chávez en Venezuela y Uribe en Colombia son ejemplos significativos. En esta dinámica, se va pasando a otro nivel del clientelismo, en donde se empiezan a utilizar las instituciones del Estado y sus recursos para construir las redes y prácticas clientelistas, que consideramos como la tercera etapa: 'clientelismo desde el Estado'.

\subsection{Políticas públicas y clientelismo}

La debilidad de los partidos, junto a la ambición de las élites de ganar respaldo político, ha llevado a que las prácticas clientelistas se trasladen a las instituciones del Estado, tarea que han hecho los mismos agentes del Estado. En este contexto, "el clientelismo se convierte en una forma del sistema de gobierno, es decir, en una manera de gestionar el poder y una forma de organizar el consenso" (Caciagli, 1996, p. 26). En tanto, el clientelismo se empieza a promover desde el Estado como parte de las reglas del juego político y de gobernanza; se toma como un instrumento viable por medio del cual el Estado se hace presente con sus responsabilidades frente a los ciudadanos.

Entre los instrumentos que se utilizan para la mediación entre el Estado y la sociedad y que han permitido, en cierta manera, seguir cultivando las prácticas clientelistas, están las políticas públicas. Aquí estaríamos en la tercera etapa del proceso clientelista que señala Caciagli (1996). Para el análisis de este documento, tomamos la interpretación que hace Velásquez de las políticas públicas, quien las define como "el proceso integrador de decisiones, acciones, inacciones, 
acuerdos e instrumentos, adelantado por autoridades públicas con la participación eventual de los particulares, y encaminado a solucionar o prevenir una situación definida como problemática" (Velásquez, 2009). En este sentido, las políticas públicas nacen con unos fines determinados y buscan casi siempre actuar sobre una realidad y modificarla o mantenerla igual. Este proceso moderno del clientelismo está muy relacionado con el uso de las políticas públicas, pues son estas producto de las disecciones muchas veces del gobierno de turno. Por eso, es necesario tomar como un punto de análisis estas políticas, ya que nos permiten examinar varias prácticas políticas, entre estas, las del clientelismo.

Para realizar un análisis más contextualizado de la transformación del clientelismo, analizamos esta tercera etapa haciendo una comparación entre los casos de Colombia y Venezuela, y particularmente entre los gobiernos de Álvaro Uribe (2002-2010) y de Hugo Chávez (1998-2010). Teniendo en cuenta lo que se ha expresado hasta este punto, las prácticas clientelistas siempre han estado vinculadas con la esfera pública y la manera de gestionar o resolver temas que afectan a los ciudadanos. Para una mejor interpretación del problema, tomamos como punto de análisis: las políticas públicas, la centralización del poder, el papel del presidente, los partidos políticos y las autoridades locales, en esta tercera etapa del clientelismo. Este tercer tema lo explicaremos en la segunda parte del artículo. Mientras tanto, ofrecemos una contextualización histórica que nos permite entender mejor el clientelismo desde el Estado.

\subsection{Un extracto histórico del fenómeno: Colombia y Venezuela}

El clientelismo se ha convertido en uno de los instrumentos que, limitadamente, permiten la articulación entre el Estado y la sociedad. En él, se encuentran varios actores que intervienen: desde el Estado, lo hacen los agentes de este (funcionarios públicos), los integrantes de la sociedad (gremios, líderes comunales, organizaciones no gubernamentales, entre otros) y los partidos políticos. Esta práctica es implementada de diversas maneras, dependiendo de los actores y el contexto. Así, "el sistema político del clientelismo opera 
no solamente de la mano del Estado, con cargos en la burocracia y obras de infraestructura, grandes y pequeñas, sino que interviene, ante todo, con el auxilio de mediadores" (Leal, 1990, p. 94). A la utilización del clientelismo como práctica política, no han escapado los partidos políticos. Adjunto a los partidos políticos, encontramos los mediadores o intermediarios, que son los enlaces más importantes entre los representantes ya sea de los partidos o del mismo gobierno y los ciudadanos del común.

No existe duda de que los partidos políticos se han apropiado de algunas de las prácticas clientelistas que implementaron los caciques locales y han adoptado unas nuevas. Los partidos han establecido su propia estructura clientelista, la cual se ha calificado como "Clientelismo partidista', 'clientelismo de los partidos' o 'partidos clientelares" (Njaim, 1996). Estos términos pueden ser aplicados a los partidos políticos que muestran una notable fortaleza, en este caso el autor se refiere a Venezuela, Costa Rica y Colombia; sin embargo, no solo el clientelismo es su instrumento político de relación con el ciudadano de a pie, junto a la ideología, se ha convertido en herramienta indispensable para que los partidos logren sumar votos.

Para el caso venezolano, los partidos consiguieron apropiarse de las prácticas clientelistas propias de los caciques y les resultó rentable en términos electorales. Veamos lo que sostiene al respecto Njaim:

Los 'patrones' tradicionales fueron expropiados de los mecanismos clientelares que habían sido funcionales a su dominación previa, pero estos mecanismos continuaron como formas llenas de un nuevo contenido que resultaron muy convenientes, porque los partidos que supieron aprovecharlas lograron una ventaja electoral considerable frente a sus adversarios tradicionales o los partidos surgidos después, que si querían competir debían adoptar de alguna manera el modelo tan exitoso que combinaba las nuevas ideologías con un hábil aprovechamiento de persistentes formas tradicionales (1996, p. 141). 
Teniendo en cuenta lo que plantea el autor, los partidos supieron apropiarse de las prácticas clientelistas tradicionales, como el pago de favores patrón/cliente. En este sentido, logran mezclar tanto el clientelismo tradicional y el nuevo con cierto grado de ideología. Entre las nuevas estrategias clientelistas, los partidos van adoptando: los trámites burocráticos, los cargos públicos, el uso de recursos públicos y la compra directa de votos, que hoy todavía se encuentra vigente. En el caso de Venezuela, los recursos provenientes del petróleo fueron importantes, esto les permitió aumentar su campo electoral; los partidos que mejor hicieron la tarea fueron: AD y Copei. En Colombia, el Frente Nacional de alguna manera permite la disminución del clientelismo, en la medida que se pacta la alternancia en el poder de los dos partidos más importantes (Liberal y Conservador), lo que disminuyó la pugna por la conquista de los votos. Sin embargo, la entrega de comida, bebida y la compra de votos no se ha eliminado. Si vamos un poco más allá, la repartición del aparato burocrático fue una estrategia que les funcionó, en la medida que les permite mantener apoyos electorales y establecer consensos.

En esta etapa del clientelismo de partidos, se empieza a hacer uso de los recursos estatales, se asignan los cargos públicos y se garantizan algunos derechos. Pero estos se han venido utilizando como instrumentos para favorecer los intereses particulares, tanto de agentes públicos como privados, especialmente de estatus social alto con relación a sus clientes. Por ejemplo, en el caso de Venezuela, el gobierno de Pérez, reconocido dirigente de Acción Democrática, se puede destacar en este contexto. Coronill sostiene que en Venezuela se promovieron prácticas clientelistas en la medida que los políticos, en particular los dirigentes, lograron "la centralización de recursos públicos hacia intereses privados que favorecerían la desmovilización de la población mediante el paternalismo y la publicidad" (2002, p. 410). Esto nos permite sostener que las prácticas clientelistas han servido como articuladoras entre el Estado y la sociedad. Lo que ha llevado a que sean utilizadas y manipuladas las instituciones del mismo Estado para establecer las relaciones de dependencia desde allí, 
y adaptarlas a las prácticas de lealtades por parte de quienes manejan el poder, aspiran a este y cuentan con recursos públicos disponibles.

Por ejemplo, la obtención de votos mediante la movilización, el uso de dinero, puestos públicos y cierto grado de ideología les han permitido a los políticos tener una estrategia compacta para lograr apoyo electoral. Estas prácticas, con el pasar del tiempo, se van convirtiendo, más que en un problema, en una forma de relación entre los ciudadanos y los partidos políticos, una práctica que simbólicamente es aceptable. Para el caso de Venezuela, Molina \& Pérez Baralt señalan que "en la base de la composición de estas lealtades partidistas se encuentra el clientelismo. La organización y la movilización de los partidarios tienen un fuerte contenido clientelar; más que eso, podemos hablar de una 'cultura clientelar', donde los partidos son percibidos por la población como dadores de beneficios de cualquier tipo, más que mecanismos de agregación de intereses y de expresión de demandas" (1998, p. 6).

En el caso de Venezuela, el Acuerdo de Punto Fijo le va a permitir a los dos partidos mayoritarios, Acción Democrática y Copei, tener cierto dominio del escenario político y, por ende, del poder del Estado, y, con esto, el control de los recursos provenientes del petróleo. En este sentido:

Los partidos asumieron en este sistema un rol preponderante, convirtiéndose en los únicos mediadores entre los ciudadanos y el sistema político. Esta intermediación fue puesta en práctica en función de una relación clientelar, que intercambiaba apoyo al sistema por beneficios materiales presentes o promesas de bienestar a futuro. En la base de este patrón está, desde luego, el modelo económico rentista. El hecho de que el Estado dispusiera de una abundante renta petrolera permitió establecer un 'sistema de botín’ donde el gobierno otorgaba beneficios más o menos cuantiosos en función de los apoyos obtenidos. No obstante lo antes dicho, el utilitarismo no constituyó la base exclusiva de este sistema (Molina \& Pérez Baralt, 1998, p. 3). 
Desde los años sesenta, Venezuela se proyectaba como una democracia estable y que buscaba, al menos en el imaginario de sus promotores y seguidores, una estabilidad política, mejor gobernabilidad y la reducción de la pobreza. Idea que predominó en los últimos gobiernos, pero esto no pasó del papel y de ser un sueño sin posibilidades de cumplirse. Como lo establece Coronill, "lo que antes se había celebrado como un Estado democrático modelo, un sistema dinámico de partidos y una economía que crecía, se describe ahora como un Estado congestionado, dominado por élites cerradas (una cogollocracia), un sistema clientelistas de partidos o "partidocracia" (2002, p. 408). El segundo gobierno de Pérez (1989-1993) fue el período en el cual floreció el clientelismo y se sumó la corrupción. En tanto, la democracia como forma de legitimación del gobierno frente a los ciudadanos tenía una débil aceptación. Esto contribuyó a que se generaran las manifestaciones sociales, el descontento militar, lo que se materializó en las calles y en algunos cuarteles militares en 1992, y posterior a esta fecha. Las revueltas callejeras, el Caracazo y el fallido golpe de Estado fueron producto en parte de que “(...) la democracia estaba convertida en una fachada detrás de la cual una élite empleaba al Estado para su propio beneficio" (Coronill, 2002, p. 419).

Para el caso de Colombia, luego que se empieza a desmontar 'aparentemente' el acuerdo del Frente Nacional, vuelven a tomar fuerza las prácticas clientelistas, cada partido o movimiento político debía ingeniárselas para llegar al poder y el clientelismo, como se ha manifestado en el caso de Venezuela, les ha ofrecido buenas posibilidades electorales.

En esta dirección, los partidos políticos establecen unos círculos políticos entre los dirigentes de los cuadros políticos, los poderes regionales y locales. Aquí los mediadores, como promotores de las prácticas clientelistas, van adquiriendo un lugar y un valor significativo. Es así como el ciudadano del común puede acceder a los beneficios que medianamente ofrece el Estado. En el caso colombiano, existe un engranaje entre los funcionarios del Estado y los ciudadanos; este 
es asumido por los intermediarios, los cuales realizan una actividad dinámica y buscan sacar el mejor provecho para su jefe político y, por supuesto, para sí mismos. Estos intermediarios trabajan muy de cerca con las autoridades municipales y departamentales, o ejercen cargos como alcaldes y concejales, lo que permite una mejor articulación de las prácticas clientelistas desde lo local hasta el ámbito nacional. En el escenario local, los partidos se especializan en el mantenimiento de sus cuadros electorales y "abandonan paulatinamente el papel de representación directa ante el Estado de los intereses de los diferentes sectores de la sociedad" (Díaz, 1986, p. 67).

Trasladándonos un poco en la historia de Colombia, para poder contextualizar mejor estas dinámicas, nos referimos a procesos que se crearon posteriores al acuerdo bipartidista (Frente Nacional). Allí, los poderes regionales logran influir en el poder central desde el mismo presidente hasta los funcionarios locales (alcaldes). Al respecto, Leal nos muestra un caso específico para Colombia, así se refiere a los hechos:

A medida que se desgastaba el destello de revitalización del nivel nacional, el presidente (López Michelsen) cultivaba con dádivas políticas el clientelismo regional. [...] la capacidad política de López logró, efectivamente, proyectar las prácticas clientelistas de provincia a nivel nacional. No se trataba ya de una articulación autoritaria de las jefaturas regionales por parte del nivel nacional, sino del ascenso de dichas prácticas a la jefatura del Estado (1989, p. 177).

Lo que se puede apreciar en esta práctica posfrente nacionalista es una proyección del clientelismo regional a un nivel nacional; esto en la medida en que los políticos de alto nivel se apoyan en los poderes regionales para, de esta manera, establecer relaciones mediante las prácticas clientelistas, que les permiten agregar apoyo local y regional a fin de alcanzar sus objetivos políticos y de poder. En el caso de Colombia, es una realidad que se establece como una forma de articular lo nacional y lo local. 
Tanto así que, desde este gobierno (López, 1974-1978), las prácticas clientelistas se empiezan a fortalecer y a imbricar desde el nivel local hasta el nacional, en donde estaban en juego los puestos públicos y los recursos del Estado, prácticas que continuaron en los posteriores gobiernos. Por ejemplo, “Turbay Ayala significó el mayor triunfo del sistema clientelista, ya que este personaje había logrado recorrer, lenta pero seguramente, la totalidad de los peldaños del ascendente laberinto político nacional utilizando los recursos disponibles en las relaciones de clientela" (Leal, 1989, p. 177). A este proceso, se sumó la descentralización que se promovió en 1986, en donde las autoridades locales y regionales se eligen por voto popular. Esta es una puerta abierta para el fortalecimiento del clientelismo local y la posibilidad de ascenso a lo nacional, en la medida en que los protagonistas vuelven a ser los intermediarios y los caciques regionales.

Para la década de los ochenta en Venezuela, no existen dudas de que el clientelismo se muestra como un negocio estratégico para tratar de controlar el poder. Un ejemplo de esto fue el Ministerio de Energía y Minas. Este Ministerio fue la torta para repartir entre los dirigentes políticos regionales y nacionales de Acción Democrática en el gobierno de Carlos A. Pérez. Su importancia se da por el manejo que se hace de los recursos y el control de alrededor de diez entes autónomos que manejaba. El control de estos pasó a manos de los 'adecos' más cercanos a Pérez, entre estos: "Empresa Petróleos de Venezuela, Bitúmenes Orinoco (Bitor), Carbones del Zulia, Fundación Guardería Infantil Min, Fundación Oro Negro, Fundelco, Palmaven, Petroquímica de Venezuela y Oficina de Servicios Geológicos y Mineros" (Miranda, 1999, p. 25).

Las prácticas clientelistas, más que un problema de la manera de hacer política, se tornan como una salida viable tanto para gobernantes y gobernados; esto en la medida en que genera posibilidades casi efectivas de lograr objetivos personales y, además, permite cierta estabilidad del mismo sistema y de las formas de gobierno. En tanto, las posibilidades para superar estas prácticas políticas no son del todo sencillas, según establece Leal, pues "no son los partidos como tales, sino su imbricación funcional con las heterogéneas prácticas 
clientelistas lo que determina su particular forma de reproducción" (1990, p. 334). Estas prácticas tienden a consolidarse en la medida en que se establecen relaciones entre empresarios y políticos.

Tanto en Venezuela como en Colombia, en el escenario de intercambio de puestos públicos por favores políticos, los partidos o sus máximos dirigentes han recurrido a una alianza que también ha mostrado resultados positivos, y es precisamente con el sector comercial, en donde se busca llegar a la sociedad allí donde los partidos no lo pueden hacer. En cuanto a la representación de los ciudadanos o la canalización de sus necesidades, los partidos no cumplen en su totalidad y "el papel ha sido asumido por las asociaciones gremiales, que abiertamente negocian en materia de política pública con la tecnocracia en sus niveles decisorios (política ganadera, de comercio exterior, transporte, salarios) al margen de los políticos profesionales" (Díaz, 1986, p. 67).

Se construye entonces una estructura de poderes (económicos, políticos y hasta militares) para ejercer la gobernabilidad, esto casi de manera planificada. Sin embargo, la eficiencia del Estado no es real y cada vez es más limitada frente a los sectores más necesitados. En este sentido, la "planeación centralizada sólo es eficiente formalmente en la medida en que tiene que dar cabida a los intereses clientelistas en el presupuesto nacional y en los cargos de dirección del Estado para garantizar la estabilidad política" (Díaz, 1986, p. 68). Con la fragmentación y debilidad de los partidos, se empiezan a construir escenarios en donde la personalización de la política se hace cada vez más evidente, especialmente con los candidatos extrapartidos. Y es precisamente aquí donde se comienza a consolidar la tercera etapa del clientelismo político: 'el clientelismo desde el Estado'.

\section{El clientelismo político desde el Estado}

\subsection{El desarrollo de las políticas públicas: los programas sociales}

Del clientelismo de partidos hemos pasado al clientelismo impulsado desde las instituciones del Estado; y, para esto, sin duda, la utilización 
de manera estratégica de las políticas públicas ha sido una constante, tanto en Colombia como en Venezuela. En Venezuela, el auge de este problema se encuentra en la promoción que se le dio a los programas sociales. Frente a las dificultades económicas que vivía Venezuela a finales de los ochenta, en parte por el mal uso de los recursos del petróleo, se generaron diferentes problemas sociales, como desempleo, problemas en el sistema de salud, aumento de la pobreza. Para lo cual, Carlos A. Pérez (1989-1993) implementó una serie de programas sociales buscando al menos mitigar estos problemas y ganar cierto respaldo de los ciudadanos. Según lo establece Méndez (1991), fueron alrededor de trece programas sociales que se implementaron desde el Estado: aumento de salarios, subsidios directos a productos de la canasta familiar, subsidios y apoyos alimenticios para estudiantes e impulso a asociaciones económicas pequeñas.

En el gobierno de Chávez, se ponen en marcha programas muy parecidos y se les imprime la parte ideológica, que les da otra dimensión. Entre los programas de tipo social (Misiones) implementados por Chávez, nos enfocamos en Barrio Adentro y Misión Mercal. En estos programas operan dos estrategias: por una parte, aliviar problemas sociales (salud, comida, vivienda, entre otros); y, por otra, mantener un cierto apoyo electoral a los gobernantes de turno, principalmente al presidente. En Venezuela, esto se manifiesta de manera clara, en la medida en que las políticas públicas son impulsadas por el gobierno central y manejadas por los gobiernos locales y los consejos comunales, y alrededor de las cuales se organiza toda una red clientelar.

En el caso colombiano, las dinámicas, guardando diferencias, son similares, pero el manejo clientelista de las políticas públicas se hace menos mediático. Sin embargo, con el fin de mitigar algunos problemas sociales, como los de agricultura, educación, salud, se crearon varios programas, entre estos: Familias en Acción y Agro Ingreso Seguro. El primero intenta ayudar a los niños que estudian dando un apoyo económico a las madres por cada hijo que asiste a la escuela; el segundo se impulsó para apoyar a los campesinos que se veían afectados por la firma del TLC con los Estados Unidos. No obstante, en épocas electorales, tanto a nivel nacional como regional, 
estos programas, particularmente el primero, han jugado un papel importante para lograr apoyos electorales de aquellos que tenían afinidad política con el gobierno de turno (Uribe).

En esta nueva etapa del clientelismo — esto es lo que nos interesa-, las prácticas clientelistas se han desarrollado utilizando las políticas públicas. Aquí el clientelismo ya no opera solamente en el ámbito local, sino que su radio se expande desde el nivel nacional. En este caso, el gobernante de turno (presidente) construye sus redes clientelistas utilizando las políticas públicas, o mejor, los recursos asignados a estas. En el caso particular de Colombia, el programa de Agro Ingreso Seguro se utilizó, en cierta medida, para pagar favores políticos, no solo representados en votos, también en apoyos económicos.

En este orden de ideas, según lo establece Chacón, "los subsidios habían sido adquiridos por personas de altos ingresos, como empresarios, modelos e hijos de senadores, además de revelar cómo varios de éstos iban a parar a la misma familia" (2010, p. 197). Aquí las políticas públicas juegan un papel importante para la implementación del clientelismo. El presidente y efectivamente el Ministro (de Agricultura) hacen uso y manejo de los recursos del Estado, en este punto los canalizan por medio de la política social para devolver apoyos políticos a varios hacendados, los cuales aportaron dinero y respaldo político a sus respectivas campañas políticas.

Este caso en Colombia requiere una especial atención, en la medida en que los recursos públicos no están directamente relacionados con la obtención de votos; sin embargo, se conoce que las familias que obtuvieron los recursos poseen cierto caudal electoral en su territorio respectivo. Según se establece en la revista Cambio, algunos de los más altos subsidios se asignaron a políticos de alta trayectoria y que de alguna manera ayudaron a la campaña de Uribe. En la revista, se afirma que el programa se utilizó con fines clientelistas, pues los recursos públicos "se han concentrado en familias de influencia política, y donantes de las dos campañas presidenciales del presidente Uribe y de la recolección de firmas para su reelección" (Cambio, agosto 
24 de 2012). Un ejemplo preciso es la familia Vives Lacouture, de la cual algunos de sus integrantes han sido senadores.

En el caso de Venezuela, los programas sociales están enfocados a promover un mejor bienestar para un cierto número de ciudadanos; sin embargo, su ejecución está amañada a lograr que el presidente obtenga apoyo electoral. En épocas electorales, el presidente aumentaba los cupos para los subsidios y quienes asignan estos cupos son, en su mayoría, seguidores del presidente Chávez, en este caso los intermediarios. Para Colombia, el programa Familias en Acción se proyecta para ayudar a las madres cabeza de familias de bajos recursos, no obstante, los políticos de turno, particularmente los del oficialismo, han hecho saber a los beneficiarios que, si no apoyan a sus candidatos, el programa puede desaparecer. Eso se evidenció en las elecciones presidenciales 2010, en donde Santos (candidato del oficialismo, hoy presidente) dio a entender que el gran promotor de dicho programa era el presidente Uribe y que él continuaría con el programa si era elegido presidente. El mensaje implícito, en Colombia, es sumar votos mediante la manifestación de continuidad o no del programa. En el caso de Venezuela, el mensaje es más directo, en la medida en que el presidente maneja de manera más centralizada los programas, además con cierto tinte ideológico. En esta nueva etapa del clientelismo, estos programas han sido, en cierta medida, manejados de manera clientelista, en tanto pueden generar votos a los políticos de turno, mediante la utilización de los recursos públicos y las mismas instituciones del Estado. Existen algunos parecidos en los dos casos en estudio: los programas están enfocados a familias de escasos recursos y buscan agregar apoyo electoral al presidente y a las autoridades locales afines con el gobierno de turno.

Los programas se enfocan a estas clases, esto en la medida en que "se trata de un votante que vela por la solución de necesidades inmediatas (...) a través de quien le ofrece ayuda, quien a su vez puede hacerlo gracias a su acceso a recursos estatales" (Cante, 2011, p. 23). En el caso de Venezuela, dicha estrategia clientelista le permitió al expresidente Chávez sumar apoyo electoral e imponerse a sus contendores 
políticos en varias ocasiones. En el caso de Colombia, el programa Familias en Acción también está encaminado a las madres cabeza de familia de estratos 1 y 2 del Sisbén. Algunos estudios, como el de Global Exchange, sostienen que el programa se ha utilizado por algunos políticos para sumar votos en sus campañas a diferentes cargos de elección popular. Existen algunos documentales y documentos en donde se explica esta realidad. ${ }^{1}$ Otros trabajos que plantean el problema de la utilización del programa para lograr votos por parte de los políticos de turno son los de Ceriscope. ${ }^{2}$ Además, se evidencia el manejo mediático y la publicidad que se hacía, de dicho programa en los consejos comunitarios, por parte del entonces presidente Uribe y por las mismas autoridades locales, entre estos quienes eran afectos al presidente.

En la medida en que todos los votos valen lo mismo a la hora de sumar, los programas y en particular el nuevo clientelismo se centran en agregar participantes en el programa; en el caso de Colombia, esto ocurre sin tener en cuenta ideología o apegos partidistas. Es preciso subrayar que con el cumplimiento de ciertos requisitos legales se accede al programa. Esto es cierto, pero no se puede desconocer el papel que juegan los políticos y los intermediarios en la asignación de los cupos para tal programa. Algunos políticos suelen utilizar su condición de candidatos para manifestar que, si el ciudadano no les retribuye apoyo electoral, es posible que dejen de recibir el beneficio, o hacen entender que son políticos generosos que impulsan el programa y que gracias a ellos este está vigente.

En este sentido, se maneja una suerte de condicionamiento, que, más que incluir a los ciudadanos en el programa, busca que el beneficiario vote por determinados candidatos. Para el caso de Venezuela, por

\footnotetext{
1 Para más información, se puede consultar: http://www.globalexchange.org/blogs/ peopletopeople/2010/06/17/groundbreaking-study-on-colombias-main-welfare-programfamilias-en-accion

2 Para tener una mejor apreciación de este problema, se puede consultar: http://ceriscope.sciences-po.fr/pauvrete/content/part2/pauvrete-et-clientelisme-electoral-en-colombie y http://ceriscope.sciences-po.fr/node/246
} 
las características del gobierno, las cosas se tornan más complejas. Las prácticas clientelistas dentro de los programas se vuelven selectivas con respecto a Colombia. Allí se busca sumar a las Misiones (programas sociales) ciudadanos afectos al proyecto chavista; esto es así en la medida en que las Misiones en su mayoría son impulsadas por los consejos comunitarios, una vez establecidos en el año 2005, y que en su mayoría son afectos al chavismo. Según lo estableció el mismo presidente, los consejos comunitarios "ejercen directamente la gestión de las políticas públicas y proyectos orientados a responder a las necesidades y aspiraciones de las comunidades en la construcción de una sociedad de equidad y de justicia social" (García, 2008, p. 13). La afiliación de los ciudadanos a estos programas depende de lo que puedan hacer los CC, los cuales dependen del presidente, en tanto "los CC de los sectores comunales también se vinculan con las Misiones y otros programas gubernamentales de carácter populista cuyo propósito ha sido 'movilizar políticamente a la población' a costa de la autonomía” (García, 2008, p. 14). Sin embargo, es preciso afirmar que los ciudadanos que no se identifican con el gobierno pueden vincularse al programa, pero el trámite burocrático no es fácil, se convierte en una manera de exclusión.

El manejo clientelista que se les está dando a estos programas sociales no solamente permite sumar ciertos votos al presidente y a sus candidatos afectos, ya sea en el nivel nacional o local, sino que, además, permite una recentralización del poder. Esto sin duda se logra, a pesar de que en las respectivas constituciones se establece la descentralización. Este tipo de recentralización se promueve de manera informal, lo que no implica mayor esfuerzo y se hace en un tiempo más corto y sin transformar de manera significativa la organización legal formal. El manejo que se hace de los recursos públicos permite que la centralización sea efectiva, en la medida en que son manejados directamente por el presidente o por alguna entidad que depende o controla el propio gobierno central. Sin duda, este es un fenómeno nuevo en esta etapa del clientelismo. 


\subsection{Presidencialismo y recentralización del poder}

A pesar de que la descentralización política y administrativa ha sido un logro que se había alcanzado medianamente, tanto en Colombia como en Venezuela, con el nuevo proceso clientelista, hoy se limita cada vez más, en la medida en que el manejo de los recursos públicos se define desde el alto gobierno.

Para el caso de Venezuela, el fenómeno se hace más visible dado que existe una estructura más o menos organizada que permite un control de las entidades nacionales, regionales y locales por parte del mismo presidente. Para poner en contexto este planteamiento, nos referimos a la manera cómo funcionan los consejos comunitarios, aquí el papel del presidente es clave en este nuevo proceso clientelista. La puesta en marcha de los CC tal vez no tenía como meta recentralizar el poder, pero por la estructura de estos y la forma de actuar en el ámbito local ha tenido este resultado. Las mismas autoridades locales así lo reconocen, puesto que los CC responden directamente a la Vicepresidencia y no a las autoridades locales. Por ejemplo:

Los alcaldes de Chacao, El Hatillo y Baruta, pertenecientes a la oposición, han sido mucho más cautelosos en tal aceptación [de los consejos comunitarios] debido a la 'supuesta' tendencia centralizadora, a su adscripción a la Vicepresidencia y no a la Alcaldía como se esperaría dentro del modelo descentralizado vigente y al solapamiento de algunas de sus funciones con las que le corresponden a la Alcaldía. Estos alcaldes de la oposición también opinan que los CC compiten con los municipios en lo que se refiere a los recursos que provienen del ejecutivo y al posible desplazamiento de la instancia municipal en los procesos de decisión local (García, 2008, p. 21).

Con respecto a esto, llama la atención que los mandatarios locales que hacen parte de la oposición al gobierno ven en los CC organizaciones que permiten la recentralización no solo del poder, sino también del manejo de los recursos. No sucede lo mismo con los mandatarios locales que pertenecen al oficialismo, ellos ven en los CC organismos 
que potencializan la participación y el trabajo en comunidad. Para citar un ejemplo, García afirma que casos como "los alcaldes Bernal de la Alcaldía Libertador y Barreto de la Alcaldía Metropolitana, ambos fichas clave del chavismo, han aceptado sin ningún cuestionamiento los CC" (2008, p. 21).

Según lo establece García, los CC han sido fichas clave en el proceso de recentralización del poder en Venezuela, esto en la medida en que no responden directamente a las autoridades locales, sino que lo hacen al gobierno del presidente de turno. Es así como "se da un solapamiento y usurpación de competencias entre los CC y el concejo municipal. Ello se debe a que, de acuerdo con su estructura funcional, los CC no dependen de los concejos municipales, sino de una comisión presidencial local que es designada por la comisión regional y, a su vez, depende de la Comisión Presidencial Nacional erigida por mandato de la Presidencia de la República” (García, 2008, p. 21).

Como hemos manifestando, los CC no son autónomos frente al poder central, el presidente fue quien los creó y los maneja, aquí el presidente tiene una fuerte influencia, esto ya que su labor depende del poder central. Por lo tanto, la mayoría de los CC son afines al chavismo y los recursos que manejan los asigna directamente el presidente o su delegado. Esto ha hecho que el presidente pueda organizar una serie de redes clientelistas que le han permitido recentralizar el poder $y$ mantener cierto apoyo electoral.

Para el caso de Colombia, la recentralización del poder se incrementó en los dos gobiernos del presidente Uribe. Teniendo en cuenta la manera como se desarrolló este proceso en Venezuela, en Colombia opera con unas dinámicas un tanto diferentes. Sin embargo, el manejo de los recursos públicos por el poder central, la organización de redes clientelares y la disminución de la autonomía de los gobiernos locales guardan similitudes. En Colombia, los intermediarios son cooptados por la misma estructura del sistema; en Venezuela, prima la exclusión, pues el manejo de los recursos depende de la cercanía con el gobierno y su propuesta política. Para el caso de Colombia, se creó la figura de los consejos comunales (reuniones del presidente 
con los ciudadanos) y un recorte a las transferencias (recursos del Estado destinados a los municipios).

La manera como el presidente Uribe adelantó su gobierno (ocho años) debilitó la descentralización y fortaleció la centralización del poder. En este sentido, utilizó los consejos comunales para gestionar algunas necesidades de los ciudadanos restando autonomía a los alcaldes, gobernadores y a los mismos concejos municipales. Conforme lo establece Sandoval, la autonomía local, la participación, la flexibilización del poder, "la planeación participativa son procesos que han sido reemplazados por los consejos comunitarios, los cuales son la expresión de un Estado intervencionista y responden al modelo uribista, el cual se erige sobre la centralización del poder y la microgerencia, debilitando la democracia y fortaleciendo el esquema presidencialista en Colombia” (2007, p. 2).

La implementación de la figura de los consejos comunitarios, antes que abrir espacios de participación para los ciudadanos, permite la ampliación del poder ejecutivo y la manipulación en el manejo de los recursos públicos. Es directamente el presidente quien resuelve algunas problemáticas locales y autoriza la entrega de recursos a los ciudadanos o a las mismas entidades locales. En esta dirección, Duarte cita al expresidente Gaviria, quien sostiene que "el presidente ha asumido un carácter centralista en los departamentos [...], prácticamente no hay un gobernador o un alcalde que pueda adelantar una obra sin que se necesite permiso de Planeación Nacional o de un ministerio o de la misma Presidencia. [...] el gobierno de Uribe Vélez [...] ha interferido las funciones de las asambleas, de los concejos y de los alcaldes, al decirle a todo el mundo qué debe hacer y supeditar todas las obras a su voluntad" (Duarte, 2011, p. 20).

De otra parte, llama la atención la manera como se han manejado las transferencias económicas. Fue en el gobierno del presidente Uribe donde mejor se centralizó el manejo de los recursos económicos de forma clientelista. En este sentido, se reduce la autonomía del gobierno local y el manejo de recursos pasa a manos del gobierno central. Un caso particular en Colombia es Acción Social, depen- 
dencia que maneja los recursos destinados al programa Familias en Acción. Este tipo de manejo, según Pedro Santana, "de lo que se trata es de recentralizar el país bajo la vieja fórmula de la Constitución de 1886. Estos recursos irán principalmente a fortalecer el presidencialismo y el centralismo en manos de la institución presidencial y de sus instrumentos directos, como, por ejemplo, Acción Social, que se ha convertido en un superministerio, el cual depende directamente de la Presidencia de la Republica" (Santana, citado en Sandoval, 2007, p. 2).

Tanto el manejo de los recursos como la implementación de los consejos comunitarios le permitieron al presidente Uribe centralizar el poder. Esto ocurre en una etapa en donde se venía avanzando en la descentralización y el fortalecimiento de la democracia participativa. Según afirma el exalcalde de Bogotá Luis Eduardo Garzón, “el solo hecho de que termine siendo reemplazado el gobernante local por el nacional es sumamente negativo, porque esto releva la responsabilidad del alcalde o del gobernador y es el presidente quien termina asumiendo funciones que no le corresponden” (Garzón, 2010).

Finalmente, es interesante aclarar que la centralización del poder tanto en Colombia como en Venezuela, en gran parte, está determinada por el papel que asume el presidente: donde hace uso de los recursos, trata cuestiones comunales e influye en el manejo de los programas sociales. La figura del presidente en los dos casos juega un papel importante, en la medida que logra recentralizar el poder, armar sus redes clientelistas y, de esta manera, lograr apoyo electoral, esto sumado a cierto grado de ideología, que en el caso de Venezuela es más evidente que en Colombia. Asistimos, entonces, a la creación de una figura institucional, mediante la cual se establecen las nuevas prácticas clientelistas. Figuras como los consejos comunales en Colombia, o comunitarios en Venezuela, utilización de la institucionalidad, el manejo de las políticas públicas y de los recursos estatales, sirven para que el presidente de manera directa resuelva problemáticas de los ciudadanos en el ámbito local. Este proceso de recentralización ha permitido crear una nueva relación entre el Estado y los ciudadanos que se ha enmarcado en la nueva etapa clientelista. 


\subsection{La nueva relación Estado-ciudadano}

Este nuevo proceso, la implementación del clientelismo desde las instituciones del Estado mediante las políticas sociales y la centralización del poder, conlleva sin duda a reorganizar o, mejor, a generar una nueva relación entre el Estado y los ciudadanos. Si en la estructura clientelista tradicional las relaciones más fuertes se establecían entre el cacique y sus seguidores o el patrón y los clientes, la relación del Estado con el ciudadano se tornaba lejana. En esta nueva etapa, las relaciones se reconfiguran en la medida en que el presidente suele estar más cerca de los ciudadanos que en el pasado; además, se debe tener en cuenta el papel que juegan los intermediarios en esta relación.

En este nuevo proceso, el ciudadano tiende a tornarse más dependiente del Estado y del mismo gobierno. La puesta en marcha de los programas sociales que se sustentan muchas veces en prácticas clientelistas abren espacio para que el ciudadano acuda al político de turno buscando obtener un beneficio: al menos ser incluido en un programa social. Es preciso aclarar que la rearticulación de las relaciones entre Estado y sociedad se evidencia mejor con las clases sociales bajas, ya que en su mayoría son las que reciben algún tipo de subsidio. En este sentido, según lo manifiesta Szwarcberg, "la existencia de recursos es la que permite fortalecer la relación y atribuirle significados. Por tanto, la proliferación de sentidos en los individuos involucrados en el lazo clientelar guarda estrecha relación con la lógica de distribución de los bienes. De hecho, es esta la que conduce a la construcción de un novedoso entramado social que permite la conformación de una red" (2001, p. 5). Las redes que se configuran alrededor de los programas sociales son las que muchas veces establecen las nuevas relaciones entre el Estado y los ciudadanos.

En el caso particular de Venezuela, estas relaciones se tornan más amañadas, dado que hay una mayor dependencia de las clases bajas frente al gobierno. Además, existe cierta organización de la comunidad alrededor de las Misiones y los coordinadores mantienen una estrecha relación con el gobierno. En este orden de ideas, "las Misiones han contribuido a la proliferación de organizaciones comunitarias, fun- 
damentalmente a través de los comités de salud y las organizaciones comunitarias de vivienda y las cooperativas" (Patruyo, 2008, p. 80). El elemento que articula estas organizaciones al gobierno es el manejo de los recursos que asigna el presidente a los programas sociales.

En esta medida, podemos pensar que, en Venezuela, las clases sociales bajas se intentan organizar alrededor de los programas sociales, los cuales son directamente manejados por el presidente; en tanto estas organizaciones se tornan más dependientes del gobierno de turno, pues les ofrecen ciertos subsidios. Además de la cercanía gobiernociudadano mediada por el uso de los recursos, no debemos dejar de lado el papel que juega la ideología y los programas mediáticos, como el de Aló Presidente, en donde se tienen en cuenta algunas opiniones de los ciudadanos. Es preciso apuntar que en Venezuela existe una suerte de control de la sociedad (beneficiarios de las Misiones), en la medida en que las organizaciones locales son manejadas por los consejos comunitarios y estos dependen directamente del gobierno central. En cuanto a esto, Acuña sostiene que estas nuevas relaciones se sustentan en la subordinación, porque existe "una dependencia jerárquica y de control. Se establecen lazos verticales basados en diferencias de poder y en desigualdad" (2009, p. 32).

Frente a Venezuela, en Colombia existe una relación un tanto más directa entre el presidente y los ciudadanos; sin embargo, menos estructurada que en el caso venezolano. Una de las estrategias que utilizó el presidente Uribe, como lo hemos manifestado, para acercar el Estado a los ciudadanos fueron los consejos comunitarios. Allí el presidente logró establecer una cercanía con los ciudadanos del común; en este sentido, "los consejos se convirtieron en una herramienta muy eficiente para la comunicación entre el gobierno y la gente, puesto que, gracias a su realización en los más variados lugares del país, se rompió la línea tradicional de intermediación, para crear una comunicación directa entre los ciudadanos y el presidente" (El país.com, 2010).

La presencia del presidente regularmente los sábados en las localidades o algunas ciudades del país, sin duda, le dio otra dimensión a la 
relación Estado-ciudadano. Estos espacios le permitían al mandatario establecer una relación directa con los ciudadanos, en donde eran resueltos de primera mano por el mandatario algunos problemas sociales, tales como vías, vivienda e infraestructura educativa. Sin embargo, esta relación se torna dependiente y un tanto condicionada, en la medida en que depende del presidente la solución de ciertos problemas locales.

El nuevo proceso clientelista contribuye a marcar unas nuevas relaciones Estado-ciudadano, hecho que es común en los dos casos en estudio. No obstante, existen sus propias particularidades. Para el caso de Venezuela, esta relación es un poco más estructurada, ya que se institucionalizan los consejos comunitarios y estos a su vez manejan casi siempre a las organizaciones comunitarias que se generaron con la puesta en marcha de los programas sociales (Misiones). La relación se puede ver como una suerte de control desde el gobierno central. Para el caso de Colombia, la relación es menos institucional y menos sectorizada; además, el uso de los medios de comunicación juega un papel fundamental. De otra parte, el control de algunos territorios por parte del ejército, que antes fueron controlados por las guerrillas, muestra en cierta medida una presencia de la autoridad del Estado, lo que estuvo acompañado de la presencia del presidente allí donde ocurrían problemas de orden público. Teniendo en cuenta lo anterior, es preciso señalar que la implementación de los programas sociales y la centralización del poder han hecho que en los dos países se rearticulen las relaciones Estado-sociedad. Por la misma dinámica de las prácticas clientelistas, las relaciones Estado-ciudadanos se van institucionalizando desde los mismos escenarios locales.

\subsection{El clientelismo: una articulación entre lo nacional y lo local}

Teniendo en cuenta lo que se ha expuesto hasta este punto, es preciso manifestar que existe un proceso de rearticulación de las prácticas clientelistas desde el nivel nacional al local. No es un clientelismo horizontal, es una estructura que se enmarca desde una vía vertical, en donde el presidente de turno es quien lleva la pauta en dicho proceso, utilizando casi siempre la institucionalidad. 
En esta medida, es el presidente quien define los programas, las personas responsables de ejecutarlos y la manera como se asignan a los ciudadanos. Para tal efecto, siempre se apoya en autoridades tanto regionales como locales. Para el caso de Colombia, son las autoridades municipales (alcalde o enlace municipal) quienes hacen la vinculación de los ciudadanos al programa Familias en Acción, cosa que no sucede con los consejos comunales, donde el presidente directamente hace la gestión. Si una persona voluntariamente quiere vincularse al programa, debe acudir a dichas autoridades para obtener el beneficio. Esta dinámica la establece el centro de investigación Foro Nacional, de la siguiente manera:

En los municipios la unidad coordinadora es la Alcaldía, la que ejecuta las actividades del programa, garantiza la oferta institucional de los sectores de educación y salud; nombra un enlace municipal, responsable de la ejecución y coordinación del programa; y apoya los diferentes procesos operativos para la vinculación de las familias beneficiarias, entre otros. El enlace municipal coordina y apoya la organización de las familias beneficiarias, participa además en la operación del sistema de seguimiento y monitoreo interno, para lo cual debe contar con el apoyo de todas las entidades de la administración municipal (Foro Nacional, 2012, p. 16).

La vinculación de los ciudadanos a la institucionalidad se hace desde el nivel local, pero responde directamente al nivel nacional, lo que hace que el programa se use, de manera coyuntural, para obtener beneficios electorales, los cuales operan desde el nivel local al nacional. Con esta organización, las relaciones institucionales, en su mayoría, no se construyen por el camino de la burocracia o la participación ciudadana, sino que más bien responden al logro de un beneficio inmediato. En el caso particular de Colombia, lograr acceder a un subsidio de un programa social.

Para el caso de Venezuela, las relaciones institucionales tienen un tinte clientelista más arraigado que en Colombia. Esto se puede explicar en la medida en que los ciudadanos se organizan desde el nivel local 
con una influencia del gobierno central, influencia que es ejercida por los integrantes de los consejos comunitarios. Aquí las alcaldías oficialistas y los CC como organizaciones institucionalizadas vinculan al ciudadano a la institucionalidad de forma clientelista. Según lo establece Patruyo (2008), la vinculación de los ciudadanos de esta manera a la institucionalidad obstaculiza la participación y la planeación en la cual los ciudadanos pueden jugar un papel importante y por este camino fortalecer los lazos entre el ciudadano y el Estado, y, por el contrario, refuerza el clientelismo.

Tanto en Colombia como en Venezuela se han generado unas nuevas relaciones entre el ciudadano y las instituciones del Estado, particularmente en el ámbito local. Sin embargo, estas relaciones institucionales ya no responden a procesos de participación y gestión; por el contrario, lo hacen a procesos de coyuntura, y muchas veces mediadas por prácticas clientelistas. Esto sin duda está relacionado con el papel que asumen las autoridades locales en esta nueva etapa del clientelismo.

\subsection{El actuar de las autoridades locales}

En esta nueva dinámica clientelista, las autoridades locales juegan un papel importante, sin duda tienen una nueva forma de actuar en el ámbito público. Como constitucionalmente se debe hacer, es de esperar que las autoridades locales respondan a lo establecido por el nivel central; efectivamente lo hacen, pero este actuar está amañado a los procesos clientelistas promovidos desde el mismo presidente. En la configuración de estas prácticas clientelistas, juegan en dos dimensiones: por una parte, reproducen las prácticas implementadas por el propio presidente, y, en un segundo plano, crean en el ámbito local, alrededor de los programas sociales, su propio clientelismo y organizan las redes a su favor.

En el caso particular de Venezuela, el proceder de las autoridades locales, cuando estas hacen parte del oficialismo, es reproducir las prácticas clientelistas impulsadas por el propio presidente. En este orden de ideas, asumen la tarea de vincular los ciudadanos a la 
institucionalidad utilizando maniobras clientelistas y, para esto, se apoyan en la ejecución de los programas sociales (Misiones). Según lo establece D'Elia, el papel de la administración local cambia, en la medida en "que está colocando sus instituciones bajo el mando de los órganos del poder revolucionario" (2008, p. 14). Aquí las autoridades locales pierden autonomía, en tanto deben responder a lo establecido por el poder central, ya que los recursos con los que cuentan dependen de la decisión del presidente.

Con respecto a esto, las administraciones locales del oficialismo se han convertido en correas de transmisión de las prácticas clientelistas impulsadas por el gobierno central. En este sentido, "las comunidades son un instrumento político más, donde la organización es importante, siempre y cuando se convierta en un grupo de presión efectivo, que le permita al gobierno local tener herramientas suficientes para lograr mayor asignación de presupuesto, y solo así se generarán cambios en el entorno de la comunidad" (Chacón, 2006). Llama la atención esta dinámica en Venezuela. Se podría creer que la acción de las autoridades locales con la comunidad está condicionada al beneficio que pueda obtener el gobernante local del propio presidente, en este caso asignación de recursos.

Para el caso de Colombia, la lógica clientelista local tiene sus particularidades. La estructura no está tan marcada como en el caso venezolano; sin embargo, las autoridades locales responden a la lógica clientelista impulsada por el nivel central. El gobierno local vincula al ciudadano a la lógica central, ya no de manera burocrática; por el contrario, lo hace en la medida en que puede garantizar cierta cantidad de recursos del gobierno central. De este modo, "el gobierno nacional requiere el concurso de las entidades territoriales para garantizar que el programa llegue a sus destinatarios. Al mismo tiempo, los municipios se benefician con los recursos entregados por el gobierno nacional a las familias" (Foro Nacional, 2012, p. 16). Esto nos da a entender que entre más ciudadanos tenga el gobierno local vinculados a los programas, en este caso al programa Familias en Acción, mayor son los recursos que recibe del nivel central. 
Parece ser que se juega a una lógica de competencia por los recursos y no por un proceso de participación y planeación de la acción pública; las autoridades locales se reacomodan a la lógica de las relaciones clientelistas impulsadas desde el nivel nacional. Pero, además, es interesante mirar el papel del gobierno local desde la acción del poder central. En este sentido, es preciso anotar que las autoridades locales juegan un papel importante en esta nueva etapa de las prácticas clientelistas, puesto que organizan las redes para responder al nivel central.

Es preciso apuntar que las prácticas clientelistas se rearticulan en el nivel regional y local, bajo la estructura nacional. Aquí tanto el presidente como las autoridades en cada territorio empiezan a jugar un papel relevante en esta dinámica, en la medida en que van organizando un proceso político sustentado en una estructura que hace uso de las instituciones del Estado y mediante las políticas públicas generan unas nuevas dinámicas clientelistas. Se han establecido redes clientelistas en donde los intermediarios, ya sean autoridades locales o particulares, asumen un papel central en el mantenimiento y muchas veces expansión de la red, buscando siempre apoyos electorales para los gobernantes de turno y afines con el presidente.

\subsection{La acción de los partidos políticos}

No podemos terminar esta reflexión sin antes dar un vistazo al papel que asumen los partidos en este nuevo proceso clientelista, los partidos se han reacomodado a las nuevas prácticas clientelistas. Pero es preciso apuntar las particularidades de los dos casos en estudio.

Para el caso de Venezuela, una vez se pone en marcha la Constitución de 1999 y la centralización del poder por parte del presidente Chávez, los partidos tradicionales se van desdibujando del escenario político. En el nuevo panorama, el partido oficialista (PSUV) asume el liderazgo e intenta ocupar el espacio de los partidos tradicionales y se muestra como mayoritario. Esto lo consigue adaptándose muy pronto a las dinámicas clientelistas impulsadas por el gobierno central. 
Ya no es el partido que busca la participación de los ciudadanos por medio del debate y la deliberación; por el contrario, se apoya en la acción de los consejos comunitarios y el manejo de los recursos de los programas sociales para sumar apoyo ciudadano. Su ampliación electoral en cierta medida la ha logrado mediante las nuevas prácticas clientelistas (uso de los programas sociales, centralización del poder y cierto grado de ideología).

De otro lado, los partidos y movimientos que no hacen parte del oficialismo se muestran como una alternativa de poder y se han organizado para hacer oposición al gobierno. Desde su punto de vista, critican el proceso clientelista mediante el cual se adelantan los programas sociales y han intentado sumar apoyo buscando abrir la participación. Han logrado sumar apoyos electorales significativos, pues en las últimas elecciones presidenciales (abril de 2013) obtuvieron alrededor del $49 \%$ del total de los votos. Faltaría precisar qué tanto de este apoyo puede estar amañado a prácticas clientelistas; sin embargo, la contienda partidista en Venezuela se está reconfigurando.

Para el caso de Colombia, las cosas son un tanto diferentes que en Venezuela. Los partidos políticos han aumentado en número, por lo menos hasta la reforma de 2003, luego de las crisis de finales del siglo pasado. En su nuevo proceso y para tener cierto protagonismo, no se han distanciado de las prácticas clientelistas que los han caracterizado: compra directa de votos, entrega de materiales, tramitología y utilización de puestos públicos. En este sentido, como sostienen Ungar y Arévalo (2004), "su misma debilidad los motivó a consolidar maquinarias clientelistas en el ámbito regional y local, dependientes de los recursos estatales" (p. 55). Por lo tanto, en el gobierno de Uribe, la mayoría de los partidos se aliaron al proyecto del presidente buscando figurar en el escenario político y lograr recursos del alto gobierno.

Algunos de estos partidos, en particular los que apoyaron al presidente Uribe, buscaron sacar ventaja de los programas sociales, como el de 
Familias en Acción. Al respecto, se manifestaron cuestionamientos; por ejemplo, al partido de la $\mathrm{U}$ se le acusa de sacar ventaja electoral del programa Familias en Acción. Según se estableció en la revista Cambio (mayo de 2010) y en el portal Votebien (abril de 2010), algunos líderes locales y regionales buscaron agregar apoyo electoral de quienes recibían el subsidio para el candidato Santos.

Hoy los partidos políticos se han articulado de cara al nuevo proceso clientelista y han adoptado algunas prácticas nuevas, como, por ejemplo, el uso de los programas sociales para sumar apoyos electorales y mantener de esta manera cierto grado de aceptación por parte de los ciudadanos y el manejo directamente de algunos recursos estatales.

Teniendo en cuenta los dos casos (Colombia y Venezuela), a manera de conclusión, podemos sostener: que se está configurando una nueva etapa en el proceso clientelista, en donde las políticas públicas y las instituciones del Estado son utilizadas por parte del presidente de turno para dinamizar dicha práctica. En este sentido, esta práctica le permite al presidente organizar una suerte de redes clientelistas, lograr ciertos consensos, pero, sobre todo, ganar apoyo electoral. La reconfiguración del clientelismo permite la recentralización del poder en la figura del presidente y, en esta medida, ha ayudado a establecer una nueva relación entre el Estado y los ciudadanos, donde los intermediarios y las autoridades locales juegan un papel importante. Por las necesidades sociales en las que se encuentran las clases sociales bajas y la posibilidad que les genera el clientelismo, se "despliega una estrategia de los clientes para acceder a los programas asistenciales del Estado, por ello está fuertemente ligado al sistema de políticas sociales" (Aguirre, 2012, p. 51). Esto nos permite afirmar que, mientras se utilicen las políticas públicas de manera clientelista, las redes clientelares seguirán aumentando y el clientelismo continuará fortaleciéndose como práctica política y forma efectiva de relacionar el Estado con los ciudadanos, aunque esto debilite la institucionalidad. 


\section{Agradecimientos}

De manera muy especial quiero agradecer al profesor Yann Basset, por su apoyo y sugerencias en este tema.

De igual forma, al profesor Bernardo Vela, por impulsarme a investigar estos temas y hacer sus comentarios.

A Johann Martínez, por sus aportes y comentarios a este trabajo.

\section{Referencias}

(s. a.). (2012). Algunos proyectos beneficiados con subsidios de Agro Ingreso Seguro habían sido declarados inviables. Cambio.

Acuña Chaverri, I. A. (2009). Elementos Conceptuales del clientelismo político y sus repercusiones en la democracia. Rev. Reflexiones, (88).

Agencia Prensa Rural. (2009a). Agro Ingreso Seguro para familias de gran tradición, influencia política y donantes de las dos campañas presidenciales.

Agencia Prensa Rural. (2009b). Agro Ingreso Seguro para familias de gran tradición, influencia politica y donantes de las dos campañas presidenciales de Uribe. Recuperado de http://prensarural.org/spip/spip.php?article2973

Aguirre, J. L. (2012). Redes clientelares. Una perspectiva teórica desde el análisis de redes sociales. Argentina: CIEPP.

Caciagli, M. (1996). Clientelismo, corrupción y criminalidad organizada. Madrid: Centro de Estudios Constitucionales.

Cante, F. (2011). ¿Son libres los votantes en Colombia? Desafios, 23(I), 15-55. Chacón Tapias, F. G. (enero-diciembre, 2010). Rawls y Nozick: dos enfoques, dos teorías, dos perspectivas sobre un mismo Agro Ingreso Seguro. Univ. Estud., (7), 193-214.

Chacón Tomiris, V. (2006). El desarrollo local y la relación Estado-comunidad en

Venezuela. Valencia: Universidad de Carabobo, Facultad de Ciencias Económicas y Sociales.

Coronill, F. (2002). El Estado mágico. Naturaleza, dinero y modernidad en Venezuela. México: Fondo de Cultura Económica.

D’Elia, Y., \& Cabezas, L. F. (2008). Las Misiones en Venequela. Caracas: Ildis. 
Díaz Uribe, E. (1986). El clientelismo en Colombia. Un estudio exploratorio. Colombia: Áncora.

Duarte, C. (2011). Descentralización y recentralización en Colombia: fases y disyunciones en la implementación de un modelo neoclásico de gobierno. Colombia: Raizal, Universidad Nacional de Colombia.

Foro Nacional por Colombia. (mayo, 2012). Elprograma Familias en Acción en Colombia: focalización territorial, relaciones intergubernamentales, organización, participación y enfoque de género. Bogotá: Foro Nacional.

García Guadilla, M. P. (2008). La praxis de los consejos comunales en Venezuela: ¿poder popular o instancia clientelas? Revista Venezolana de Economia y Ciencias Sociales, 14.

Leal Buitrago, F., \& Dávila, A. (1990). Clientelismo: el sistema político y su expresión regional. Colombia: Tercer Mundo Editores.

Leal Buitrago, F. (1989). Estado y politica en Colombia. Colombia: Editorial Siglo XXI.

Méndez, A. (1991). La política social en el gobierno de Carlos Andrés Pérez (1989-1990). Revista Acción Critica, (29).

Miranda, P. (1999). Contradicciones, ilicitudes y corrupción durante 40 años de Punto Fijo. Caracas: Editorial Sextante.

Molina, J. E., \& Pérez Baralt, C. (marzo-abril, 1998). Luces y sombras de la democracia venezolana. A 40 años del 23 de enero. Nueva Sociedad, (154).

Njaim, H. (septiembre-octubre, 1996). Clientelismo, mercado y liderazgo partidista en América Latina. Nueva Sociedad, (145).

O’Donnell, G. (1995). Estado, democracia y ciudadanía. En P. Santana (Comp.), Las incertidumbres de la democracia. Bogotá: Foro Nacional por Colombia.

ONG Global Exchange. (2010). Aumentan los subsidios, aumentan los votos. Votebien. Recuperado de http://www.terra.com.co/elecciones_2010/ votebien/html/vbn1004-aumento-de-votos-y-subsidios-estatales.htm

Patruyo, T. (2008). El estado actual de las Misiones. Balance sobre su proceso de implementación e institucionalización. Venezuela: Ildis.

Sandoval, M. Y. (2007). La recentralización en el gobierno Uribe. Bogotá: Corporación Viva la Ciudadanía.

Szwarcberg, M. L. (2001). Alimentando lealtades. Un análisis del lazo clientelar: el caso de las Manzaneras. Universidad Torcuato Di Tella. 
Ungar, E., \& Arévalo, C. A. Partidos y sistema de partidos en Colombia hoy: ¿crisis o reordenación institucional? Recuperado de http:/ / www.idea.int/publications/upload/Partidos $\% 20 y \% 20$ sistemas $\%$ en $\% 20$ Colombia $\% 20$ hoy.pdf

Velásquez Gavilanes, R. (2009). Hacia una nueva definición de concepto de 'política pública'. Desafíos, 20(I), 149-187.

Weber, M. (2002). Economía y sociedad. México: Fondo de Cultura Económica. 
